\title{
Variance of elemental concentrations of organic products: the case of Brazilian coffee
}

Rafaela DEBASTIANI ${ }^{\mathrm{a}, \mathrm{d}^{*}}$, Carla Eliete lochmis DOS SANTOS ${ }^{\mathrm{b}}$, Mateus Maciel RAMOSa, Vanessa Sobrosa SOUZAc, Livio AMARALa, Johnny Ferraz DIAS ${ }^{a}$

alon Implantation Laboratory, Institute of Physics, Federal University of Rio Grande do Sul, Av. Bento Gonçalves, 9500, CP 15051, CEP 91501970, Porto Alegre (RS), Brazil.

bInstitute of Mathematics, Statistics and Physics, Federal University of Rio Grande, Campus Santo Antônio da Patrulha, Rua Barão do Caí 2274, CEP 95500-000, Santo Antônio da Patrulha (RS), Brazil

'Institute of Mathematics, Statistics and Physics, Federal University of Rio Grande, Campus Carreiros, Av. Itália, km 8, CEP 96201-900, Rio Grande (RS), Brazil

d Institute of Nanotechnology, Karlsruhe Institute of Technology, Hermann-von-Helmholtz-Platz 1, 76344, Eggenstein-Leopoldshafen, Germany

Corresponding author:

Rafaela DEBASTIANI*: rafaela.debastiani@kit.edu +4972160826358 Institute of Nanotechnology, Karlsruhe Institute of Technology, P.O. Box 3640, 76021 Karlsruhe, Germany 


\section{Abstract}

Elemental composition can be used to help determining the origin and quality of food and beverage. The present study aims to investigate the variation of the elemental composition of a Brazilian coffee brand across different production batches. To that end, 102 samples from 11 different batches of "Melitta Tradicional" roasted ground coffee were analyzed using the Particle-Induced X-ray Emission (PIXE) technique. The concentrations of $\mathrm{Mg}, \mathrm{Al}, \mathrm{Si}, \mathrm{P}, \mathrm{S}, \mathrm{Cl}, \mathrm{K}, \mathrm{Ca}, \mathrm{Ti}, \mathrm{Mn}, \mathrm{Fe}, \mathrm{Cu}, \mathrm{Zn}$ and $\mathrm{Rb}$ were determined. Differences in the elemental concentrations between at least two batches were observed for all investigated elements but Ti. For elements such as $\mathrm{Cl}, \mathrm{Ca}, \mathrm{Cu}$ and $\mathrm{Rb}$ the concentration varied over $50 \%$ between batches. The differences observed among batches indicate that the characterization of coffee by brand or origin is not a straightforward task.

Keywords: Coffee, minerals, PIXE, elemental concentration, ground coffee 
Coffee is among the world's most consumed beverages and constitutes a very important commodity for countries such as Brazil, Vietnam and Colombia. Contributing in 2018 with $37 \%$ of the global crop production, Brazil is the largest producer and also an important consumer, behind European Union and United States only [1]. The Brazilian coffee plantation corresponds to more than 2.2 million hectares allocated mainly in 6 Brazilian states (Minas Gerais, Espírito Santo, São Paulo, Bahia, Rondônia and Paraná) producing predominantly Arabica coffee ( $80 \%$ of the plantation area) [2].

The control of quality and origin of coffee is usually based on the determination of different compounds as volatile compounds, caffeine, lipids, carbohydrates, polysaccharides, vitamin B3, tannins, trigonelline, chlorogenic acid and minerals. Methods such as atomic spectroscopy and mass spectroscopy are commonly used in order to identify suitable markers to provide authenticity and origin of coffee and its infusions [3]. However, during the coffee production from growing to roasting, the chemical composition of coffee may be changed as soon as harvesting takes place. According to Pohl et al., the mineral content in the coffee, which corresponds to about $5 \%$ of total composition, can be used as good indicator to the authenticity of coffee [3].

Although many scientific methods have been proposed to solve the problems of authenticity and origin of coffee $[3,4]$, the determination of such parameters may not be so straightforward when it comes to commercial roasted ground coffee. Popular commercial roasted ground coffee is usually traded in vacuum-tight packages in order to prolong their shelf life. Moreover, such coffees are either packed with Robusta, Arabica or just a blend of them. The coffee beans are produced by several farms from different locations and may be processed in agricultural cooperatives units or large processing plants. In most cases, no information is given neither about the blend nor the origin of the coffee beans. As the final composition of food and beverage depends on several factors including soil, environmental pollution, field practices, use of pesticides and fertilizers [5], the determination of the 
elemental composition and chemical compounds of retail coffee may be affected in those cases where popular ground coffee is concerned.

Regarding the power to discriminate coffee from different producers through the elemental composition, the studies are carried out usually using coffee samples from only one package per brand. For instance, Grembecka et al. investigated 60 coffees of non-specified origin or type of blend from different countries and continents. Although more than one sample was prepared for each coffee, only one package per brand was used [4]. Vega-Carrillo et al. investigated the elemental concentration of ground and instant coffee from 12 brands produced by 7 different companies. Again, only one package per brand was analyzed [6]. Anderson and Smith investigated roasted bean coffees from eight countries analyzing only one package of coffee per country. As far as Brazilian coffee is concerned, the very limited number of samples is also a common characteristic in the studies. Tagliaferro et al. studied whole beans and roasted ground coffee of several brands, but only one package per brand [7]. On the other hand, Zaidi et al. do not inform the amount of coffee beans purchased [8].

In our previous study [9] we demonstrated that the analysis of a small number of packages may be misleading regarding the elemental composition of coffee. In this case [9], three packages corresponding to 2 different batches were analyzed for eight brands of popular Brazilian coffee. In general, there was no significant difference among packages. However, for one particular brand, one of the packages presented a much higher elemental concentrations ( 2 to 3 times) than the other brands.

In order to verify the variance of the elemental concentrations of different batches of roasted ground coffee, samples from 11 batches of Melitta Tradicional ground coffee were analyzed using the Particle-Induced X-ray Emission (PIXE) technique. PIXE has been used for the elemental analysis and characterization of foodstuff as wine $[10,11]$, mate tea leaves $[12,13]$, canned tuna $[14]$ and coffee $[9,15]$. PIXE is an attractive technique for the elemental analysis of foodstuff in general due to the relative simple sample preparation without any wet treatment besides its non-destructive feature 
$[9,11]$. In addition, PIXE is a multielemental and fully quantitative technique with a relatively short acquisition time (in the order of $300-400$ s per sample).

\section{Material and Methods}

\subsection{Samples}

Eleven different batches from Melitta roasted ground coffee ("Melitta Tradicional") were selected in order to verify the influence of the period of manufacture in the elemental composition of coffee. The batches were named in sequence respecting the date of manufacture. Thus batch 1 corresponds to the first coffee produced, while batch 11 is the last one, with a difference of 2 years and 5 months between them. The difference of manufacturing time between two consecutive batches varied from 8.5 months (between batches 1 and 2) to only 1 day (batches 7 and 8 ). Table 1 provides the information about the batches.

In total, 102 samples were prepared by pressing $1.5 \mathrm{~g}$ of roasted coffee direct from its packages into pellets of $25 \mathrm{~mm}$ of diameter.

Table 1: Batches information: number of packages, number of samples and difference of manufacture time between 2 consecutives batches.

\begin{tabular}{llll}
\hline Batch & $\begin{array}{l}\text { Number of packages } \\
\text { per batch }\end{array}$ & $\begin{array}{l}\text { Number of samples per } \\
\text { batch }\end{array}$ & $\begin{array}{l}\text { Time between manufacturing dates } \\
\text { of two consecutives batches }\end{array}$ \\
\hline $\mathbf{1}$ & 2 & 10 & 8.5 months \\
\hline $\mathbf{2}$ & 1 & 6 & 2 months \\
\hline $\mathbf{4}$ & 1 & 6 & 6 months \\
\hline $\mathbf{5}$ & 1 & 3 & 4 months \\
\hline $\mathbf{6}$ & 2 & 3 & 2 days \\
\hline $\mathbf{7}$ & 2 & 6 & 1 month \\
\hline $\mathbf{8}$ & 1 & 6 & 1 day \\
\hline $\mathbf{9}$ & 4 & 3 & 3 months \\
\hline $\mathbf{1 0}$ & 5 & 24 & 3 months \\
\hline $\mathbf{1 1}$ & 1 & 30 & 2 months \\
\hline
\end{tabular}




\subsection{Experiments and data analysis}

Particle-Induced X-ray Emission (PIXE) was used to determine the major, minor and trace

107

108

109

\subsubsection{PIXE}

Major, minor and trace elements were determined by PIXE through the excitation of the atoms from the sample by a $2 \mathrm{MeV}$ proton beam provided by a $3 \mathrm{MV}$ Tandetron accelerator located at lon Implantation Laboratory, on Federal University of Rio Grande do Sul, Brazil. Up to 10 samples pressed in form of pellets ( $25 \mathrm{~mm}$ diameter) were placed in sample holder at the same time. The samples were positioned in a vacuum chamber (pressure about $10^{-6} \mathrm{mbar}$ ) insulated from the accelerator with the help of an electromechanical system and a camera for visualization. Each sample was measured during $400 \mathrm{~s}$ with an average current of $3 \mathrm{nA}$, and the characteristic X-rays were detected by a Si (Li) detector (energy resolution of $155 \mathrm{eV}$ at $5.9 \mathrm{keV}$ ) placed at $135^{\circ}$ with respect to the proton beam. An electron flood gun was used in order to avoid the charge buildup in the samples [16].

\subsubsection{Data Analysis}

For the PIXE data analysis, apple leaves standard (NIST 1515) and the software package GUPIXWIN [17] were used. Through the standardization procedure, experimental parameters were included in the analysis. GUPIXWIN fits all the peaks of the spectrum simultaneously using physical parameters such as secondary fluorescence, ionization cross section and ion stopping power. For each peak, an element is assigned and the elemental concentration is determined, as well as limit of detection (LOD) and uncertainties arising from the least-square fitting procedure and the experimental parameters [18]. 
129 group of samples. Values below LOD were excluded from the mean calculation, and the uncertainties

130 correspond to the standard deviation. In order to compare different group of samples, statistical

131 analysis were performed using F-test, T-test, ANOVA One Way and Tukey's Post hoc (significance level

132 of 0.05$)$.

133 


\section{Results and Discussion}

\subsection{Elemental composition of Melitta coffee}

The elemental concentration of several batches of Melitta roasted ground coffee was analyzed with PIXE technique for comparison purposes with the general composition of Brazilian coffee determined in our previous work [9]. The results are shown in Table 2.

Table 2: Mean concentrations and the respective standard deviations given in $\mu \mathrm{g} / \mathrm{g}$ for Melitta coffee $(n=102)$ and Brazilian coffee $(n=144)$. Brazilian coffee corresponds to the mean concentration of 8 brands studied in our previous work [9]. Equal letters mean statistical equality $(\alpha=0.05)$.

\begin{tabular}{|c|c|c|}
\hline Elements & Melitta coffee $(n=102)$ & Brazilian coffee $(n=144)$ \\
\hline $\mathrm{Mg}$ & $1776 \pm 167^{a}$ & $2092 \pm 323^{b}$ \\
\hline Al & $83.5 \pm 25.6^{a}$ & $90.8 \pm 26.4^{a}$ \\
\hline $\mathrm{Si}$ & $77.9 \pm 28.2^{a}$ & $91 \pm 37^{b}$ \\
\hline$P$ & $1475 \pm 128^{a}$ & $1761 \pm 303^{b}$ \\
\hline $\mathrm{S}$ & $1261 \pm 111^{a}$ & $1313 \pm 180^{b}$ \\
\hline $\mathrm{Cl}$ & $321 \pm 54^{a}$ & $384 \pm 79^{b}$ \\
\hline $\mathrm{K}$ & $21258 \pm 1498^{a}$ & $22451 \pm 3436^{b}$ \\
\hline $\mathrm{Ca}$ & $1441 \pm 276^{a}$ & $1437 \pm 303^{a}$ \\
\hline $\mathrm{Ti}$ & $7.2 \pm 3.3^{a}$ & $7.5 \pm 2.9^{a}$ \\
\hline $\mathrm{Mn}$ & $31.8 \pm 5.1^{a}$ & $32.2 \pm 7.7^{a}$ \\
\hline $\mathrm{Fe}$ & $60.7 \pm 17.3^{a}$ & $68.5 \pm 23.0^{b}$ \\
\hline $\mathrm{Cu}$ & $18.6 \pm 3.5^{a}$ & $18.5 \pm 4.6^{a}$ \\
\hline $\mathrm{Zn}$ & $8.65 \pm 2.55^{a}$ & $8.74 \pm 2.54^{a}$ \\
\hline $\mathrm{Rb}$ & $41.7 \pm 14.7^{a}$ & $48.5 \pm 20.2^{b}$ \\
\hline
\end{tabular}


evaluation. However, for elements such as $\mathrm{Al}, \mathrm{Si}$ and $\mathrm{Ti}$ about one third to one half of the measured samples presented concentration below LOD. The results for Brazilian coffee correspond to the mean concentration of 144 samples, including 18 samples of the Melitta brand [9]. Although the mean concentrations seem similar between the Melitta coffee and overall Brazilian coffee, statistical differences were found for $\mathrm{Mg}, \mathrm{Si}, \mathrm{P}, \mathrm{S}, \mathrm{Cl}, \mathrm{K}, \mathrm{Fe}$ and $\mathrm{Rb}$, while the variances are equal only for $\mathrm{Al}, \mathrm{Si}$, $\mathrm{Ca}, \mathrm{Ti}$ and Zn.

The lower elemental concentrations found in Melitta coffee in comparison with other brands of Brazilian coffee was also observed in our previous work despite the relatively small number of samples per brand $(n=18)$. However, comparing the mean concentration of Melitta coffee found in both works, the present work has found higher mean concentrations than the previous one [9]. This result can be related to the fact that the current work is handling a much larger number of samples and batches which may reflect a more truly representative result for this brand. On the other hand, Tagliaferro et al. [7] analyzed coffee obtained from local market in Brazil, including Melitta roasted ground coffee, and found concentrations similar to those reported here. When compared with our previous study of Melitta coffee beans [15], the concentration of the elements $\mathrm{P}, \mathrm{Cl}, \mathrm{K}, \mathrm{Fe}$ and $\mathrm{Rb}$ are higher in the roasted ground coffee. In contrast, the concentrations are higher in the beans samples for elements such as Mg (1841 $\mu \mathrm{g} / \mathrm{g})$, Ca $(1633 \mu \mathrm{g} / \mathrm{g})$ and $\mathrm{Mn}(41 \mu \mathrm{g} / \mathrm{g})$.

The standard deviations reported in Table $\mathbf{2}$ are relatively higher for Brazilian coffee than for the Melitta coffee. Concerning the elements with highest concentration, the standard deviation of $\mathrm{Mg}$, $\mathrm{P}$ and $\mathrm{K}$ for Brazilian coffee are at least twice the ones for Melitta coffee. However, for the trace elements such as $\mathrm{Fe}, \mathrm{Cu}$ and $\mathrm{Rb}$, the differences between the two groups are smaller (about $30 \%$ ). Thus, these results indicate that even the mean concentration between one determined brand and a general mean of several brands are similar, it is possible to observe the individuality of the brands through their variances. 


\subsection{Elemental composition of different batches of Melitta coffee}

Differences in the elemental concentration between batches of the Brazilian coffee No Bule were observed in our previous work [9]. Three packages corresponding to 2 batches (packages 1 and 2 from one batch and package 3 from another batch) of ground coffee were analyzed with PIXE technique and the mean concentration of package 3 was found to be 2 to 3 times the mean concentration of the packages 1 and 2 [9]. In order to extend the study regarding such differences, we selected the popular brand Melitta to analyze 11 batches of ground coffee. The information about the batches is shown in Table 1. For comparison among different batches data, the ANOVA and Tukey's Post hoc statistical tests (significance level of 0.05) were employed.

Table 3 shows the results of all batches studied in this work. The PIXE analysis identified the same elements in all batches. However, Al, Si and Ti were found below or compatible with the LOD in batches $4,5,7$ and 11 . Ti was the only element with equal mean concentration among the batches, while the remaining elements presented differences between at least 2 batches. Among the elements with highest concentration, namely $\mathrm{K}, \mathrm{Mg}$ and $\mathrm{P}$, the mean concentration varied from 17821, 1620 and $1329 \mu \mathrm{g} / \mathrm{g}$ (batches 1, 9 and 1) to 22994, 1896 and $1580 \mu \mathrm{g} / \mathrm{g}$ (batches 7, 10 and 7) (see Table 3). Concerning micro and trace elements, large differences were also observed among the batches. Actually, much higher concentration (about twice) was detected for elements such as $\mathrm{Cl}, \mathrm{Ca}, \mathrm{Ti}, \mathrm{Mn}$, $\mathrm{Fe}, \mathrm{Cu}, \mathrm{Zn}$ and $\mathrm{Rb}$ among batches. For instance, the mean concentration of $\mathrm{Rb}$ from batches 8 and 11 corresponds to $(58 \pm 6) \mu \mathrm{g} / \mathrm{g}$ and $(50 \pm 12) \mu \mathrm{g} / \mathrm{g}$, while the concentration found for batch 3 is $(22.4 \pm$ 3.7) $\mu \mathrm{g} / \mathrm{g}$.

Looking into Table 3, it is possible to observe two distinguished groups in the elemental analysis of the batches. Observing the values, the mean concentrations for the batches 1 to 5 (group "a") seem to be relatively lower when compared with batches 6 to 11 (group "b"). However, some exceptions were observed for both groups. For example, the mean concentration of some elements such as $\mathrm{Mg}, \mathrm{P}, \mathrm{S}$ in batch 9 are closer to values found in group "a", while the elements $\mathrm{Mg}, \mathrm{P}, \mathrm{S}, \mathrm{Ca}, \mathrm{Cu}$ 
and $\mathrm{Rb}$ from batch 4 have concentration higher than the rest of the group "a". It worth to note that manufacture date of the batches 5 and 6 is only 2 days apart from each other, and although the mean concentrations of several elements of batch 6 seem to be higher, they are statistical equal for all elements but $\mathrm{K}$. The batches 7 and 8 were manufactured with only 1 day of difference and their elemental concentrations are statistically equal for all the elements. Concerning the batches with the lowest and highest concentration, the mean concentrations are different between all of them but Al, $\mathrm{Si}, \mathrm{Ti}$ and $\mathrm{Zn}$.

Individually, the elements from some batches presented concentration compatible with literature, as is the case of $\mathrm{K}, \mathrm{Ca}, \mathrm{Cu}$ and $\mathrm{Rb}$. The mean concentrations of $\mathrm{K}$ for the batches 1 and 2 are compatible with the values found by Fernandes et al. for conventional $(17000 \mu \mathrm{g} / \mathrm{g})$ Brazilian green coffee beans [19], as well as batches 4 and 6 to 11 are in the range of values found for Brazilian roasted ground coffee by Tagliaferro et al. $(20800-22700 \mu \mathrm{g} / \mathrm{g})$ [7]. Our results show Brazilian coffee has a concentration much higher of $\mathrm{K}$ when compared to the ground coffee from Turkish local markets analyzed by Özdestan, which varied from $7732 \mu \mathrm{g} / \mathrm{g}$ to $11207 \mu \mathrm{g} / \mathrm{g}$ [20]. The concentrations determined for Ca and Rb were also similar with the ones found by Fernandes et al. (2002) [19] and Tagliaferro et al. (2000) [7], and the concentration of Ca is in general higher than the founds of Ashu and Chandravanshi and Grembecka et al. for roasted ground coffee [4,21]. In addition, the mean concentration of $\mathrm{Cu}$ in the batches 9,10 and 2 to 7 were consistent with the values determined by Fernandes et al. for green coffee and Grembecka et al. for roasted ground coffee $[4,19]$. In contrast to these results, our results show lower mean concentrations for elements such as $\mathrm{Mg}, \mathrm{P}, \mathrm{S}$ and $\mathrm{Mn}$ compared with literature in general. The concentration of $\mathrm{Cl}$ is higher in the present work when compared with the values found for the green coffee beans [19] and roasted coffee beans [15]. The presence of $\mathrm{Cl}$ has been associated with musty and moldy odor in coffee [22] and wine [23]. 
Table 3: Mean concentration and standard deviation in $\mu \mathrm{g} / \mathrm{g}$ for 11 batches of roasted ground coffee "Melitta Tradicional". Different subscript letters within the rows represent statistically significant differences.

\begin{tabular}{|c|c|c|c|c|c|c|c|c|c|c|c|}
\hline & 1 & 2 & 3 & 4 & 5 & 6 & 7 & 8 & 9 & 10 & 11 \\
\hline $\mathrm{Mg}$ & $1720 \pm 149 \mathrm{ab}$ & $1803 \pm 140 \mathrm{ac}$ & $1710 \pm 49 \mathrm{ac}$ & $1861 \pm 183 \mathrm{ac}$ & $1775 \pm 142 \mathrm{ac}$ & $1773 \pm 133 \mathrm{ac}$ & $1886 \pm 141_{b c d}$ & $1780 \pm 110 \mathrm{ac}$ & $1620 \pm 92 \mathrm{a}$ & $1896 \pm 178_{c d}$ & $1823 \pm 73 \mathrm{ac}$ \\
\hline Al & $127 \pm 49_{a}$ & $97 \pm 17 \mathrm{ab}$ & $67 \pm 10_{a b}$ & $\angle \mathrm{LOD}$ & $123 \pm 75_{\mathrm{ab}}$ & $139 \pm 50_{\mathrm{ab}}$ & LOD & $79 \pm 25 a b$ & $61 \pm 8 b$ & $76 \pm 17 b$ & $91 \pm 24_{a b}$ \\
\hline Si & $101 \pm 28 \mathrm{a}$ & $63 \pm 23 a b$ & $77 \pm 15_{a b}$ & $94 \pm 44_{\mathrm{ab}}$ & LOD & $83 \pm 55 a b$ & LOD & $<L O D$ & $75 \pm 23_{a b}$ & $65 \pm 15_{b}$ & LOD \\
\hline $\mathbf{P}$ & $1329 \pm 88 a$ & $1452 \pm 125 \mathrm{ab}$ & $1408 \pm 51_{\mathrm{ab}}$ & $1533 \pm 101_{\mathrm{ab}}$ & $1468 \pm 83_{\mathrm{ab}}$ & $1555 \pm 90_{b c}$ & $1580 \pm 92 b c$ & $1503 \pm 183 \mathrm{ab}$ & $1376 \pm 100_{\mathrm{a}}$ & $1551 \pm 98 \mathrm{bc}$ & $1561 \pm 124 \mathrm{bc}$ \\
\hline$S$ & $1074 \pm 133 \mathrm{a}$ & $1126 \pm 102_{a b}$ & $1144 \pm 61_{\mathrm{ac}}$ & $1305 \pm 20_{\text {cde }}$ & $1149 \pm 82_{\text {adf }}$ & $1307 \pm 90_{\text {def }}$ & $1414 \pm 80_{\mathrm{eg}}$ & $1410 \pm 151_{\mathrm{eg}}$ & $1221 \pm 47_{b c f h}$ & $1355 \pm 57$ ei & $1324 \pm 48_{\mathrm{dghi}}$ \\
\hline $\mathrm{Cl}$ & $342 \pm 30 a$ & $233 \pm 14 b$ & $256 \pm 30 \mathrm{bc}$ & $257 \pm 4$ bd & $316 \pm 29$ abe & $385 \pm 32$ af & $343 \pm 48 \mathrm{ad}$ & $412 \pm 81_{\text {af }}$ & $351 \pm 32$ af & $298 \pm 40_{\text {cdeg }}$ & $351 \pm 48_{\mathrm{ag}}$ \\
\hline K & $17821 \pm 2022 \mathrm{a}$ & $17944 \pm 1263 \mathrm{a}$ & $\begin{array}{c}19249 \pm 408 \\
\text { ab }\end{array}$ & $\begin{array}{c}20520 \pm 463 \\
\text { bcd }\end{array}$ & $\begin{array}{c}19061 \pm 1407 \\
\text { ac }\end{array}$ & $\begin{array}{c}22156 \pm 1268 \\
\text { de }\end{array}$ & $22994 \pm 416$ ef & $\begin{array}{c}22930 \pm 1290 \\
\text { deg }\end{array}$ & $21391 \pm 559 \mathrm{dg}$ & $21698 \pm 663 \mathrm{df}$ & $22914 \pm 943 \mathrm{egf}$ \\
\hline $\mathrm{Ca}$ & $979 \pm 133 \mathrm{a}$ & $1189 \pm 250_{\mathrm{ab}}$ & $1124 \pm 111_{\mathrm{ac}}$ & $\begin{array}{c}1586 \pm 148 \\
\text { bcde }\end{array}$ & $1378 \pm 97_{\mathrm{ad}}$ & $\begin{array}{c}1576 \pm 215 \\
\text { bde }\end{array}$ & $1667 \pm 204_{\mathrm{de}}$ & $2083 \pm 597$ e & $1515 \pm 205_{b d}$ & $1540 \pm 245_{d}$ & $1479 \pm 135_{\mathrm{bcd}}$ \\
\hline Ti & $9.2 \pm 4.3 \mathrm{a}$ & $6.7 \pm 2.2 \mathrm{a}$ & $9.3 \pm 3.9 \mathrm{a}$ & $9 \pm 1.2 \mathrm{a}$ & LOD & $12 \pm 12.7_{\mathrm{a}}$ & $10.7 \pm 6.3_{a}$ & $<L O D$ & $5.5 \pm 1.1_{a}$ & $6.4 \pm 1.9 \mathrm{a}$ & $6.4 \pm 1.1_{a}$ \\
\hline $\mathrm{Mn}$ & $28 \pm 6_{a b}$ & $27 \pm 5.6_{\mathrm{ab}}$ & $29 \pm 3.3_{\mathrm{abc}}$ & $23 \pm 3.4 \mathrm{ab}$ & $28.3 \pm 2.6_{b d}$ & $33 \pm 4.5_{b d}$ & $31 \pm 3.8_{b d}$ & $34 \pm 5.4_{b d}$ & $37 \pm 6_{d}$ & $30 \pm 3_{a b c}$ & $37 \pm 7_{\mathrm{cd}}$ \\
\hline $\mathrm{Fe}$ & $75 \pm 22 \mathrm{ab}$ & $61 \pm 31_{\mathrm{ab}}$ & $48 \pm 5 b$ & $56 \pm 7 \mathrm{ab}$ & $99 \pm 85_{a b}$ & $124 \pm 123 \mathrm{a}$ & $51 \pm 13_{b}$ & $54 \pm 12 \mathrm{ab}$ & $59 \pm 7.4 b$ & $59 \pm 12 b$ & $55 \pm 15_{a b}$ \\
\hline $\mathrm{Cu}$ & $12.3 \pm 3 a$ & $15.1 \pm 2.3 \mathrm{ab}$ & $15.5 \pm 2.2 \mathrm{abc}$ & $\begin{array}{c}19.6 \pm 4.0 \\
\text { abcde }\end{array}$ & $16.5 \pm 2.6_{\mathrm{abcf}}$ & $18 \pm 2.4_{\mathrm{abcf}}$ & $22 \pm 3 \mathrm{df}$ & $26 \pm 6_{d}$ & $19 \pm 2$ bf & $20 \pm 3_{c f}$ & $25 \pm 4$ de \\
\hline $\mathrm{Zn}$ & $6.8 \pm 2.9 \mathrm{a}$ & $7.1 \pm 2.7 \mathrm{ab}$ & $8.3 \pm 2.9_{a b}$ & $7.6 \pm 3.0 \mathrm{ab}$ & $6.5 \pm 1.8 \mathrm{ab}$ & $9.2 \pm 2.9_{\mathrm{ab}}$ & $12 \pm 5.4_{b}$ & $8.8 \pm 2.8 \mathrm{ab}$ & $10 \pm 2 b c$ & $8.1 \pm 1.8 \mathrm{ac}$ & $12.2 \pm 2.0_{b}$ \\
\hline $\mathbf{R b}$ & $26 \pm 4.5 \mathrm{a}$ & $31.8 \pm 8.5_{a b}$ & $22.4 \pm 3.7_{a}$ & $46 \pm 13 \mathrm{ac}$ & $26.1 \pm 1.5 \mathrm{ac}$ & $34 \pm 13_{\mathrm{abd}}$ & $38 \pm 14_{\mathrm{ac}}$ & $58 \pm 6_{\text {bce }}$ & $52 \pm 13_{\text {cde }}$ & $48 \pm 13_{\text {bce }}$ & $50 \pm 12$ bce \\
\hline
\end{tabular}


227 necessary deeper analysis than the employed by literature. These differences can be due several

228 factors, such as soil, fertilizers and pesticides, the industrial process, as well as the use of coffee from

229 different farms and the presence of impurities such as leaves and soil in the ground coffee.

230

231

232 

different batches of this popular Brazilian coffee through the Particle-Induced X-ray Emission technique. concentration and variance for the elements $\mathrm{Mg}, \mathrm{Si}, \mathrm{P}, \mathrm{S}, \mathrm{Cl}, \mathrm{K}$, Fe and $\mathrm{Rb}$ when compared with the mean concentration of Brazilian coffee. Melitta ground coffee from 11 batches produced within 2 years and 5 months were analyzed and the results demonstrate that different batches presented different elemental concentrations. In some cases like $\mathrm{Rb}$, the difference in the mean concentration between batches varied over $50 \%$. For other elements such as $\mathrm{Mg}, \mathrm{K}$ and $\mathrm{Mn}$, the differences among batches were not so substantial. Statistical differences between at least 2 batches were observed for all elements but Ti. Concerning batches with highest and lowest concentrations, the mean concentrations for most of the elements were found to be statistically different between them. These differences can be the result of several factors which influence in the elemental composition of foodstuff, such as soil, environmental conditions, use of pesticides and/or fertilizers and field practices.

PIXE has demonstrated to be an efficient technique in the determination of elemental composition of foodstuff. The analysis of coffee from different batches has shown that the determination of the provenance may be a far more complex task than suggested in previous works.

\section{Acknowledgement}

This work was partially supported by CAPES (Coordenação de Aperfeiçoamento de Pessoal de Nível Superior) and CNPq (Conselho Nacional de Desenvolvimento Científico e Tecnológico). R. Debastiani thanks CNPq for the scholarship PDJ number 167567/2017-9. Finally, this work was developed within the scope of the IAEA Coordinated Research Project F11021 under contract number 21125. 
258 [1] ICO, International Coffee Organization, (2018). www.ico.org/ (accessed January 2, 2018).

259 [2] Conab, Acompanhamento da Safra Brasileira: café, 2017. http://www.conab.gov.br.

260 [3] P. Pohl, E. Stelmach, M. Welna, A. Szymczycha-Madeja, Determination of the Elemental 261 Composition of Coffee Using Instrumental Methods, Food Anal. Methods. 6 (2013) 598-613. doi:10.1007/s12161-012-9467-6.

[4] M. Grembecka, E. Malinowska, P. Szefer, Differentiation of market coffee and its infusions in view of their mineral composition, Sci. Total Environ. 383 (2007) 59-69. doi:10.1016/j.scitotenv.2007.04.031.

[5] H.-D. Belitz, W. Grosch, P. Schieberle, Food Chemistry, 4th ed., Springer Berlin Heidelberg, Berlin, Heidelberg, 2009. doi:10.1007/978-3-540-69934-7.

[6] H.R. Vega-Carrillo, F.Y. Iskander, E. Manzanares-Acuña, Elemental content in ground and soluble / instant coffee, J. Radioanal. Nucl. Chem. 252 (2002) 75-80.

[7] F.S. Tagliaferro, E. Fernandes, E.J. França, Elemental Composition of Commercial Brazilian Coffee using Neutron Activation Analysis, in: Int. Conf. Isot., Vancouver, 2000: pp. 277-279.

[8] J.H. Zaidi, I. Fatima, M. Arif, I.H. Qureshi, Determination of trace elements in coffee beans and instant coffee of various origins by INAA, J. Radioanal. Nucl. Chem. 267 (2006) 109-112. doi:10.1007/s10967-006-0015-y.

[9] R. Debastiani, C.E.I. dos Santos, M.M. Ramos, V.S. Souza, L. Amaral, M.L. Yoneama, J.F. Dias, Elemental analysis of Brazilian coffee with ion beam techniques: From ground coffee to the final beverage, Food Res. Int. J. 119 (2019) 297-304. doi:10.1016/j.foodres.2019.02.007. 
Yoneama, J.F. Dias, Elemental characterisation of Cabernet Sauvignon wines using ParticleInduced X-ray Emission (PIXE), Food Chem. 121 (2010). doi:10.1016/j.foodchem.2009.11.079.

281

[11] C.E.I. dos Santos, R. Debastiani, V. Sobrosa Souza, D.E. Peretti, P. Fernandes Costa Jobim, M.L. Yoneama, L. Amaral, J.F. Dias, The influence of the winemaking process on the elemental composition of the Marselan red wine, J. Sci. Food Agric. (2019) jsfa.9704. doi:10.1002/jsfa.9704.

[12] R. Giulian, C.E.I. dos Santos, S. de M. Shubeita, L.M. da Silva, M.L. Yoneama, J.F. Dias, The study of the influence of industrial processing on the elemental composition of mate tealeaves (Ilex paraguariensis) using the PIXE technique, Food Sci. Technol. 42 (2009) 74-80. doi:10.1016/j.Iwt.2008.05.007.

[13] R. Giulian, C.E.I. dos Santos, S. de M. Shubeita, L.M. da Silva, J.F. Dias, M.L. Yoneama, Elemental Characterization of Commercial Mate Tea Leaves (Ilex paraguariensis A. St.-Hil.) before and after Hot Water Infusion Using Ion Beam Techniques, J. Agric. Food Chem. 55 (2007) 741-746. doi:10.1021/jf062456r.

[14] L.A. Boufleur, C.E.I. dos Santos, R. Debastiani, M.L. Yoneama, L. Amaral, J.F. Dias, Elemental characterization of Brazilian canned tuna fish using particle induced X-ray emission (PIXE), J. Food Compos. Anal. 30 (2013) 19-25. doi:10.1016/j.jfca.2013.01.002.

[15] R. Debastiani, C.E.I. dos Santos, M.L. Yoneama, L. Amaral, J.F. Dias, Ion beam analysis of ground coffee and roasted coffee beans, Nucl. Instruments Methods Phys. Res. Sect. B Beam Interact. with Mater. Atoms. 318 (2014) 202-206. doi:10.1016/j.nimb.2013.05.105.

[16] S.M. Shubeita, C.E.I. dos Santos, J.L.R. Filho, R. Giulian, L. Meira, P.R. Silva, L. Amaral, J.F. Dias, M.L. Yoneama, Residual activity induced by ion bombardment on insulating samples, Nucl. Instruments Methods Phys. Res. Sect. B Beam Interact. with Mater. Atoms. 240 (2005) 297302. doi:10.1016/j.nimb.2005.06.133. 
303 [17] J. Campbell, T. Hopman, J. Maxwell, Z. Nejedly, The Guelph PIXE software package III: Alternative proton database., Nucl. Instr. Meth. Phys. Res. B. 170 (2000) 193-204.

[18] S.A.E. Johansson, J.L. Campbell, K.G. Malmqvist, Particle-induced X-ray emission spectrometry (PIXE), Wiley, 1995.

[19] E.A.D.N. Fernandes, F.S. Tagliaferro, A. Azevedo-Filho, P. Bode, Organic coffee discrimination 308

[20] Ö. Özdestan, Evaluation of bioactive amine and mineral levels in Turkish coffee, Food Res. Int. 61 (2014) 167-175. doi:10.1016/j.foodres.2013.12.027.

[21] R. Ashu, B.S. Chandravanshi, Concentration levels of metals in commercially available ethiopian

[22] H. Kato, K. Sato, T. Takui, Analysis of Iodine-like (Chlorine) Flavor-causing Components in Brazilian Coffee with Rio Flavor, Food Sci. Technol. Res. 17 (2011) 347-352.

[23] J. Prescott, L. Norris, M. Kunst, S. Kim, Estimating a "'consumer rejection threshold"' for cork taint in white wine, Food Qual. Prefer. 16 (2005) 345-349. doi:10.1016/j.foodqual.2004.05.010. 